\title{
Characterization and Cytotoxic Evaluation of Silver and Gold Nanoparticles Produced with Aqueous Extract of Lavandula dentata L. in Relation to K-562 Cell Line
}

\author{
Barbara Justus $^{1^{*}}$ \\ https://orcid.org/0000-0003-3943-9304 \\ Andrés Fernando Montenegro Arana ${ }^{1}$ \\ https:// orcid.org/0000-0002-0133-2766 \\ Melissa Marques Gonçalves ${ }^{2}$ \\ https:// orcid.org/0000-0002-6524-2188 \\ Karen Wohnrath ${ }^{1}$ \\ https://orcid.org/0000-0002-3606-9275 \\ Patrícia Mathias Döll Boscardin ${ }^{1}$ \\ https:// orcid.org/0000-0001-6092-043X \\ Carla Cristine Kanunfre ${ }^{1}$ \\ https:// orcid.org/0000-0002-2865-3084 \\ Jane Manfron Budel ${ }^{1}$ \\ https:// orcid.org/0000-0003-1873-2253 \\ Paulo Vitor Farago ${ }^{1}$ \\ https://orcid.org/0000-0002-9934-4027 \\ Josiane de Fátima Padilha de Paula ${ }^{1}$ \\ https:// orcid.org/0000-0002-2717-8867
}

${ }^{1}$ State University of Ponta Grossa, Pharmacy Department, Ponta Grossa, Paraná, Brazil. ${ }^{2}$ Federal University of Paraná, Pharmacy Department, Curitiba, Paraná, Brazil.

Received: 2018.12.12; Accepted: 2019.08.30.

*Correspondence: barbara.justus@hotmail.com; Tel.: +55-42-99926-2551 (B.J.) 


\title{
HIGHLIGHTS
}

- Lavandula dentata L. extract reduces silver to metallic nanoparticles in a simple green method.

- Metallic nanoparticles as chemotherapeutic agent.

\begin{abstract}
Metallic nanoparticles have great potential as a chemotherapeutic agent. The aim of this study was to develop and characterize silver and gold nanoparticles using a simple method, as well as evaluating the potential cytotoxic activity in relation to the K-562 cell line. For the synthesis, a solution containing the metallic ions was subjected to magnetic stirring with the aqueous extract of Lavandula dentata $L$. and a change of colour was observed. With the data obtained from the analyses we concluded that the nanoparticles were successfully obtained by a simple and green method using the aqueous extract of $L$. dentata. The obtained nanoparticles presented a reduced size, a low level of polydispersion, and a homogenous spherical shape. The nanoparticles presented intense and characteristic diffraction peaks, which could be correlated to the planes of the centred cubic structure of the silver and gold. The two formulations presented predominantly crystalline characteristics. The infrared analysis suggested that the amides and alcohols present in the samples may have been responsible for the reduction and limitation of the size and dispersion of the silver and gold nanoparticles. The cytotoxic assay showed that the nanoparticles demonstrated great potential to reduce the cell viability of the K-562 cell line, especially the gold nanoparticles.
\end{abstract}

Keywords: green synthesis; metallic nanoparticles; myelogenous leukemia line; cytotoxic potential; Lamiaceae.

\section{INTRODUCTION}

Due to its varied applications, materials, and forms of development, nanotechnology has been used in several areas, which has been reflected in high levels of investment in this technique. The search for improved quality, competitiveness and increased productivity has led industries to increase their interest in nanoparticles, targetting nanoelectronic characteristics such as catalysis, paramagnetism, optical properties, good conductivity, applications in food industries, and water treatment. Nanoparticles have also been used as antimicrobial agents in materials such as prostheses, catheters, dental materials, and also as chemotherapeutic agents [1]. However, this investment is costly since metallic nanoparticles are very expensive; therefore, it is necessary to seek low-cost methods to produce them [1]. Other metals have been studied regarding the development of nanoparticles, but colloidal solutions of silver and gold have special characteristics [2].

Colloidal silver nanoparticles were introduced in 1910, when they were used to treat burns, nervous disorders and syphilis because they present high antimicrobial activity in relation to gram-positive and gram-negative bacteria, fungi and viruses. Their activity 
depends on the size of the particles, allowing greater contact of the nanoparticles with the cells. The interaction of nanoparticles with the interior of the cell leads to damage in the process of cellular respiration, as well as DNA damage, which prevents cell division [3, 1].

Nanoparticles can be produced by reducing metal ions using nitrate, alcohols, carbohydrates, ascorbic acid, sodium citrate, sodium borohydride, formaldehyde and hydrazines, among others. This reduction is due to the characteristic of nanoparticles to donate electrons to the metal cations. The reducing substance is one of the materials responsible for the definition of particle size. In addition to the reducing agents already mentioned, green agents can be used to form nanoparticles, thereby focusing on an environmentally friendly and safe mode of synthesis [4].

Lavandula dentata L. (Lamiaceae) presents potential for use in this reduction because its extract contains a large quantity of phenolic compounds such as coumaric acid; hexoside (3,4-dihydroxyphenyl)-2-hydroxylpropanoic acid; hydroxyhydrocinnamic acid glucoside; yunnaneic acid; methyl caffeate; rosmarinic acid; apigenin di-C-hexoside; luteolin 7,4'-di-glucuronide; apigenin C-hexanediol isomer 1; apigenin C-hexoside isomer 2; isoscutellarein 8-O-glucuronide; luteolin 7-O-glucuronide; luteolin 7-O-glucoside; and apigenin 7-O-glucoside, genkwanin [5]. L. dentata is a small perennial shrub native to the Mediterranean which grows on rocky and arid terrain; it has clumps of quadrangular and woody stems. It is used in folk medicine as an antidiabetic agent, to treat common colds, and for renal colics such as antispasmodic and antiprotozoal [6]. The L. dentata species was selected for the present study due to its wide use in folk medicine, its great pharmacotherapeutic potential, and its widespread availability.

The K-562 cell line is derived from a patient with chronic myelogenous leukemia (CML), which affects 1-2 individuals per 100,000 people. It is predominant in men between the ages of 40 and 60 , but it can also affect individuals up to 20 years of age. It corresponds to approximately $15 \%-20 \%$ of all leukemias [7], and metallic nanoparticles have great potential as a chemotherapeutic agent. The aim of this study was to develop and characterise silver and gold nanoparticles using a simple method, as well as evaluating the potential cytotoxic activity in K-562, a chronic myelogenous leukemia (CML) cell line.

\section{MATERIALS AND METHODS}

\section{Preparation of the extract}

The vegetative aerial parts of $L$. dentata were collected from the medicinal garden of the General Pharmacy course at Ponta Grossa State University (UEPG), Paraná, Brazil. They were identified by a taxonomist and carefully washed with distilled water to remove all visible, undesirable particles. Subsequently, $20 \mathrm{~g}$ of this material was weighed into a beaker, filled with $1,000 \mathrm{ml}$ of distilled water, and subjected to heating. Sixty minutes after boiling it was set aside at room temperature. It was then filtered through a $0.24 \mu \mathrm{m}$ pore filter and the resultant was stored at $4-8{ }^{\circ} \mathrm{C}$.

\section{Synthesis of silver nanoparticles (LdAgNPs)}

For the synthesis of the silver nanoparticles, an aqueous solution of $1 \mathrm{mM}$ silver nitrate $\left(\mathrm{AgNO}_{3}\right)$ was prepared; $1 \mathrm{~mL}$ of this solution was placed under magnetic stirring with $9 \mathrm{~mL}$ of 
aqueous extract of $L$. dentata. The reduction of the $\mathrm{Ag}^{+}$ions was completed and confirmed by a change in colour, from colourless to colloidal orange $\left(\mathrm{Ag}^{0}\right)$. The solution was stored in the dark at $4-8{ }^{\circ} \mathrm{C}$ until further analysis.

\section{Synthesis of gold nanoparticles (LdAuNPs)}

For the synthesis of the gold nanoparticles, an aqueous solution of $1 \mathrm{mM}$ gold salt $\left(\mathrm{HAuCl}_{3}\right)$ was prepared, and $1 \mathrm{~mL}$ of this solution was placed under magnetic stirring with 9 $\mathrm{mL}$ of aqueous extract of $L$. dentata. The reduction of the $\mathrm{Au}^{+3}$ ions was completed and confirmed by the change in colour from yellow gold to ruby red $\left(\mathrm{Au}^{0}\right)$. The solution was stored in the dark at $4-8^{\circ} \mathrm{C}$ until further analysis.

\section{Characterisation of nanoparticles}

\section{UV - Visible spectroscopy analysis}

Wavelength readings were performed to monitor the formation of nanoparticles by the presence of characteristic plasmon bands, and also to study the stability of the nanoparticle solutions. The analyses were carried out using UV-Vis Nir Varian CARY 50 equipment in scan mode, in the 200-800 nm range with quartz cuvettes.

\section{Determination of zeta potential}

The zeta potential of the developed nanoparticles was analysed using a Zetasizer Nano ZS90 (Malvern Instruments) apparatus with an angle of incidence of $90^{\circ}$ to $25^{\circ} \mathrm{C}$. The suspensions were prepared with Millipore Milli-Q system water in a 1:10 ratio (v:v) and then analysed in triplicate.

\section{Atomic force microscopy (AFM)}

For the analysis of atomic force microscopy, SHIMADZU SPM 9600 AFM equipment was used, with a model NCRH-20 Nanoworld aluminum-coated silicon cantilever, with 42 $\mathrm{N} / \mathrm{m}$ constant, a resonance frequency of $320 \mathrm{kHz}$, and a thickness of $4 \mu \mathrm{m}$. The experiments were performed in non-contact mode (phase contrast).

\section{Transmission electron microscopy (TEM)}

The size and shape of the synthesised gold and silver particles were determined by TEM (JEOL JEM 1200 EX-II). A drop of a diluted sample was placed on the Cu grid, covered with a thin film, and allowed to dry. The instrument was operated with an accelerating voltage of $200 \mathrm{KV}$.

\section{$X$-Ray diffraction}

The nanoparticles were analysed using an Ultima IV (Rigaku) X-ray diffractometer with scans of $2 \% \mathrm{~min}$ from 5 to $80 \AA$, copper Ka radiation $(\lambda=1.5418 \AA), 30 \mathrm{~mA}$ current, and $40 \mathrm{kV}$ voltage to observe peaks that were possibly indicative of crystallinity. The suspensions were oven dried at $36 \stackrel{\circ}{\circ}$ until powder formation for subsequent analysis. 


\section{Fourier-transform infrared spectroscopy (FTIR)}

The nanoparticles were analysed by Fourier-transform infrared spectroscopy to evaluate the functional groups involved in the formation of the nanoparticles. For each sample, a tablet was prepared by cold pressing, which was composed of potassium bromide $(\mathrm{KBr})$ at spectroscopic grade $(2 \% \mathrm{w} / \mathrm{w})$ and the powder formed by the nanoparticle to be analysed. The readings were performed using IR Prestige 21 equipment (Shimadzuß) with $64 \mathrm{scans} / \mathrm{min}$ and a resolution of $4 \mathrm{~cm}-1$; the experimental window of interest of 4,000 to 400 $\mathrm{cm}-1$ was considered. Pure $\mathrm{KBr}$ pellets were used for the baseline reading.

\section{Cell viability assay}

The cell viability assay, or MTT, used a colour reaction to measure the number of viable cells. The tetrazolium ring of this substance is cleaved in active mitochondria, forming violet-coloured crystals that can be read by spectrophotometry when solubilised in dimethylsulfoxide (DMSO) [8].

A quantity of $1.75 \times 10^{5}$ cells $/ \mathrm{mL}$ were separated and centrifuged. The supernatant was removed and a 1:1 suspension containing either nanoparticles, or the aqueous extract, or the negative control (sterile distilled water), and a concentrated RPMI medium containing $2 \mathrm{mM} \mathrm{L}$ - glutamine, $1 \mathrm{mM}$ sodium pyruvate, $2,000 \mathrm{mg} / \mathrm{L}$ sodium bicarbonate and $10 \%$ fetal bovine serum were added. Subsequently, $500 \mathrm{uL}$ of this suspension was seeded in 24-well plates. After 72 hours of treatment, the supernatant was discarded and $400 \mu$ of a 0.5 $\mathrm{mg} / \mathrm{mL}$ MTT solution was added to the cells, following the methodology of Mosmann (8). The cultures were incubated at $37^{\circ} \mathrm{C}$ for two hours, away from light, until an observation of the presence of the formazan crystals was performed. For the solubilisation of these crystals, $200 \mu \mathrm{L}$ of dimethylsulfoxide (DMSO) was added. The spectrophotometric reading of the absorption was performed at a wavelength of $550 \mathrm{~nm}$ in a plate reader (Biotek, $\mu$ Quant).

\section{RESULTS}

\section{UV-Visible spectroscopy analysis}

UV-Visible spectroscopy analysis was used for both analyses to observe nanoparticle formation after the reduction reaction, and also to monitoring stability. UV-Vis spectroscopy analysis is commonly used for metallic nanoparticles, mainly gold and silver. These nanoparticles have a strong absorption band in the visible region, which is the result of the coherent oscillation of the free electrons induced by the interaction with the electromagnetic field formed by the incident light. This surface plasmon resonance (SPR) is characteristic of nanoparticles and does not appear when the isolated metal is analysed. In addition, this SPR effect may reveal the shape and size of the nanoparticles [9]. According to the literature, an increase in nanoparticle size results in a shift in the plasmonic band to regions of greater wavelength [1]. This increase and nucleation is dependent on the reducing and stabilising agent, as well as the temperature and $\mathrm{pH}$; an excess of reducing agent may aid stabilisation [10].

The silver nanoparticles showed a characteristic orange colour, with a peak centred around $414 \mathrm{~nm}(371 \mathrm{~nm}-458 \mathrm{~nm}$ ) (Figure 1A). According to the literature, a peak around 
$400 \mathrm{~nm}$ is characteristic of a spherical shape [3]. These results were similar to those found by Bunghez et al., 2015 [11], who developed a silver nanoparticle with aqueous extract of Lavandula angustifolia Mill. using an ultrasonic bath at $30{ }^{\circ} \mathrm{C}$. Differently from the nanoparticles obtained with the $L$. dentata extract without ultrasonic bath of temperature, the nanoparticles presented different forms such as triangles, and a peak at $435 \mathrm{~nm}$.
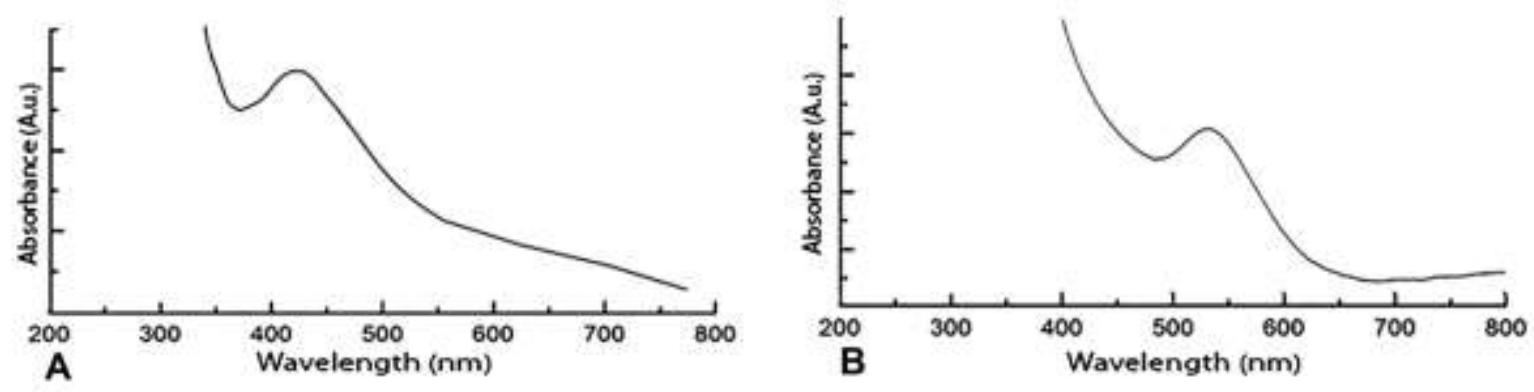

Figure 1. UV-Vis spectra of nanoparticles obtained with silver (A) and gold (B).

The gold nanoparticles presented a red-ruby colouration, which is characteristic of this metal [12], with a peak centred around $527 \mathrm{~nm}(494 \mathrm{~nm}-560 \mathrm{~nm}$ ) (Figure 1B). It is important to mention that the tendency to aggregation and sedimentation of dispersed nanoparticles as a function of time can be verified by UV-Vis, with determination of changes in particle size distribution [13]. From the results that were obtained, both the silver and gold nanoparticles presented excellent stability as a function of the maximum analysis time (thirty days); the profile of the peaks remained, as well as the intensity of absorption.

\section{Determination of zeta potential}

The polydispersity index was used to verify homogeneity in the size of the nanoparticles. According to the manufacturer (Malvern Instruments), a value of 0.08 to 0.7 is considered the average polydispersity value; above 0.7 is a very broad polydispersity value. The analysed samples presented ideal values; 0.444 for the silver nanoparticles and 0.501 for the gold nanoparticles. Thus, we consider that the nanoparticles were homogeneous with respect to size.

Regarding the analyses performed in the Zetasizer ${ }^{\circledR}$ apparatus, the obtained nanoparticles presented a Zeta potential of $-17.1 \mathrm{mV}$ and $-9.17 \mathrm{mV}$ for silver and gold, respectively (Table I). The zeta potential, or surface potential, is the ratio of the functional group dissociation at the particle surface or adsorption of ionic species present in the aqueous dispersion medium [13]. It is known that when nanoparticles have a Zeta potential value greater than $30 \mathrm{mV}$ or lower than $-30 \mathrm{mV}$ this suggests greater system stability [10]. However, this potential value is dependent on the $\mathrm{pH}$ of the suspension. Extremely acidic or basic $\mathrm{pH}$ values have ideal potential values, while $\mathrm{pH}$ values close to neutrality $(6.0-7.0)$ present potential values not expected for the stability of a nanoparticulate system. However, the zeta potential value does not determine stability, and, in addition, this $\mathrm{pH}$ range is ideal for most biological systems [3]. 


\section{Atomic force microscopy (AFM)}

The most commonly used technique for the study of the size of nanoparticles is microscopy. This provides direct images of the particles and it is also necessary to confirm the homogeneity of the sample [13]. Surface analysis by non-contact atomic force microscopy showed that both the silver (Figure 2A) and gold nanoparticles (Figure 2B) had an average size of $30 \mathrm{~nm} \pm 10 \mathrm{~nm}$, using an indirect method of measurement. Microscopy proved the efficiency of obtaining the nanoparticles due to their spherical shape, smooth surface, small size and low dispersibility.

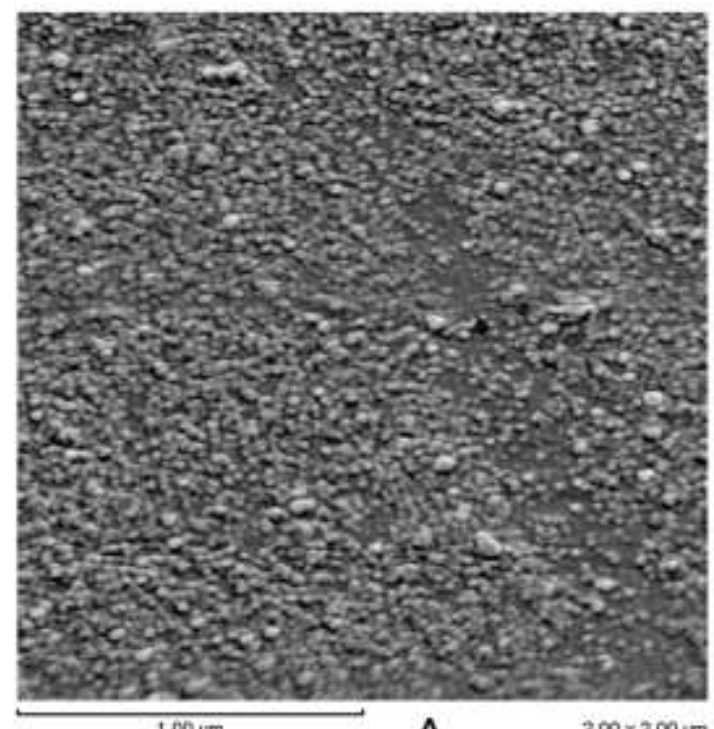

A
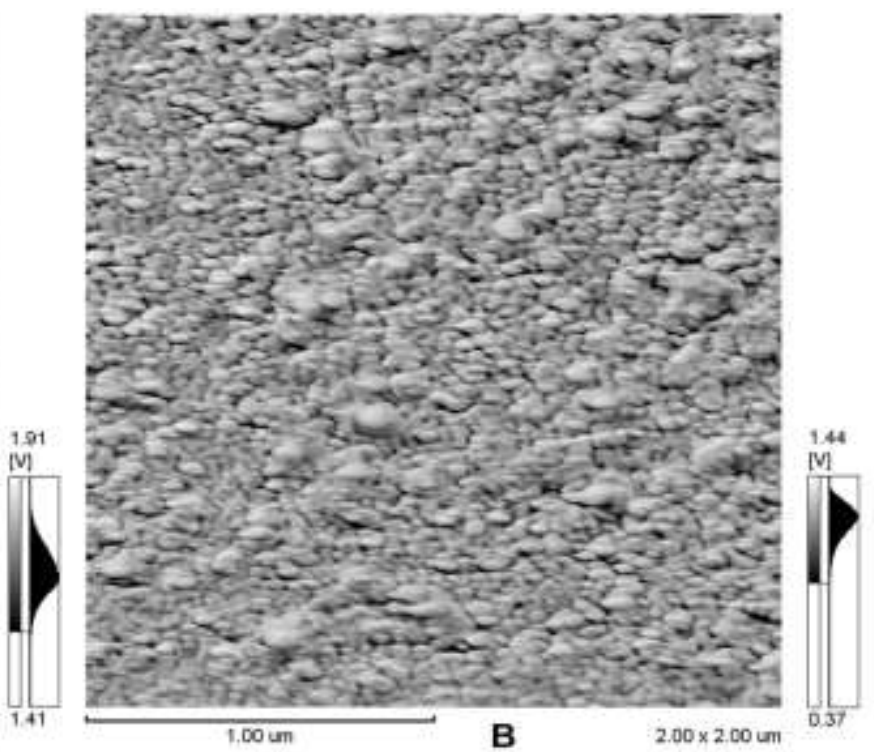

Figure 2. Images of nanoparticles obtained by TEM technique for silver (A) and gold (B) nanoparticles.

\section{Transmission microscopy}

Using the TEM technique, a beam of photons is transmitted through an ultra-thin specimen and the beam interacts with the specimen as it passes through. TEM analysis is recommended for nanoparticles because the technique uses electron beams, which can better define the size and shape of the particles. When the electrons are transmitted through the specimen an image is formed from the interaction [14]. The TEM images confirmed the results obtained in both the Zetasizer ${ }^{\circledR}$ apparatus and the atomic force microscopy, i.e. small nanoparticles with a spherical shape. This proved that the formulation used was optimal to obtain small particles with good uniformity and a well-defined shape for the silver (Figure 4A) and gold nanoparticles (Figure 4B). 


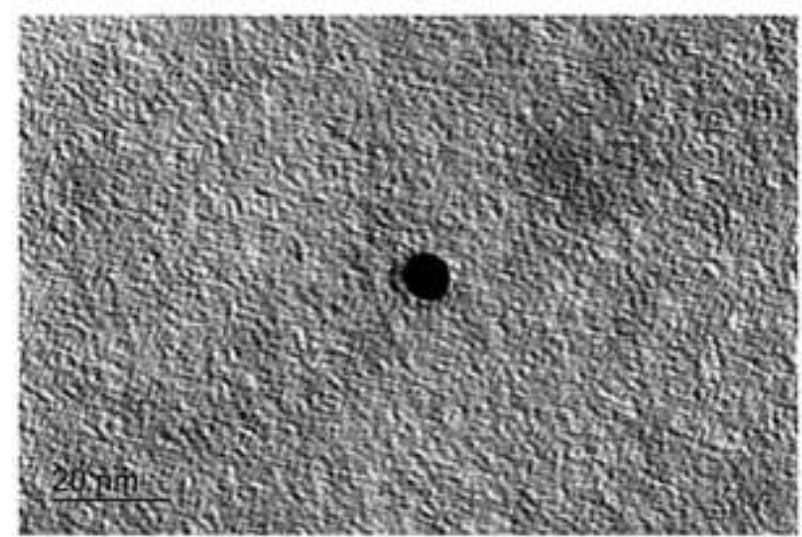

A

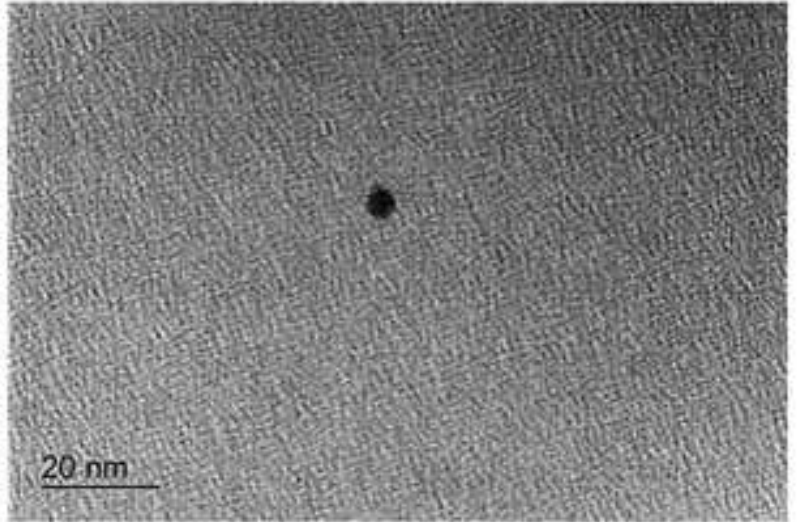

B

Figure 3. Images of nanoparticles obtained by TEM technique for silver (A) and gold (B) nanoparticles.

\section{X-Ray diffraction analysis}

The spectra obtained in the X-ray diffraction analysis of the extracts showed predominantly amorphous characteristics, which was due to the fact that it was a natural product (Figure 4 - Ext).
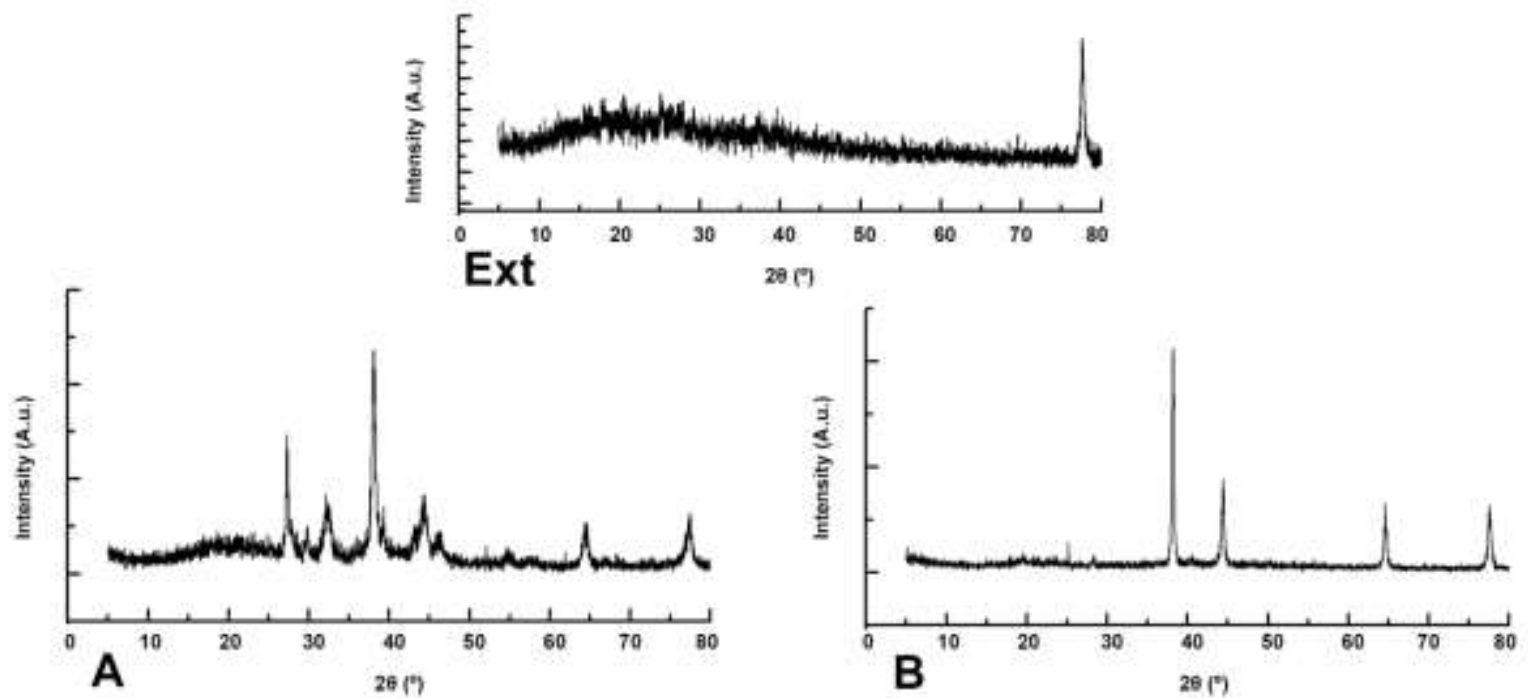

Figure 4. X-ray diffraction of aqueous extract (Ext) and nanoparticles obtained from silver $(A)$ and gold (B).

In the X-ray diffraction analysis of the silver nanoparticles it was possible to observe intense and characteristic diffraction peaks at $38^{\circ}, 44-46^{\circ}, 64^{\circ}$ and $77^{\circ}$, which could be correlated to the planes (111), (200), (220) and (311) of the centred cubic structure of the silver (Figure $4 A)[15,10,16]$. In the case of the gold nanoparticles, the peaks at $38^{\circ}, 44^{\circ}$, $64^{\circ}$ and $78^{\circ}$ were attributed to the planes (111), (200), (220) and (311) of the centred cubic face of the metallic gold (Figure 4B). In the two formulations, the highest intensity peaks were characteristic of the plane (111), which demonstrated a predominantly crystalline characteristic. 


\section{Analysis by fourier-transform infrared spectroscopy (FTIR)}

FTIR analysis was carried out to identify the functional groups responsible for the reduction of chloroauric acid and silver nitrate, as well as the stabilisation of the LdAuNPs and LdAgNPs. Due to the reduction of the $\mathrm{Au}$ and $\mathrm{Ag}$ ions should be coupled with the oxidation of the extract, we analysed any possible oxidation of the extract using FTIR analysis. Figure 5 shows the FTIR spectra of the extract-capped gold and silver nanoparticles, which were compared to the extract spectrum (Figure 5a).

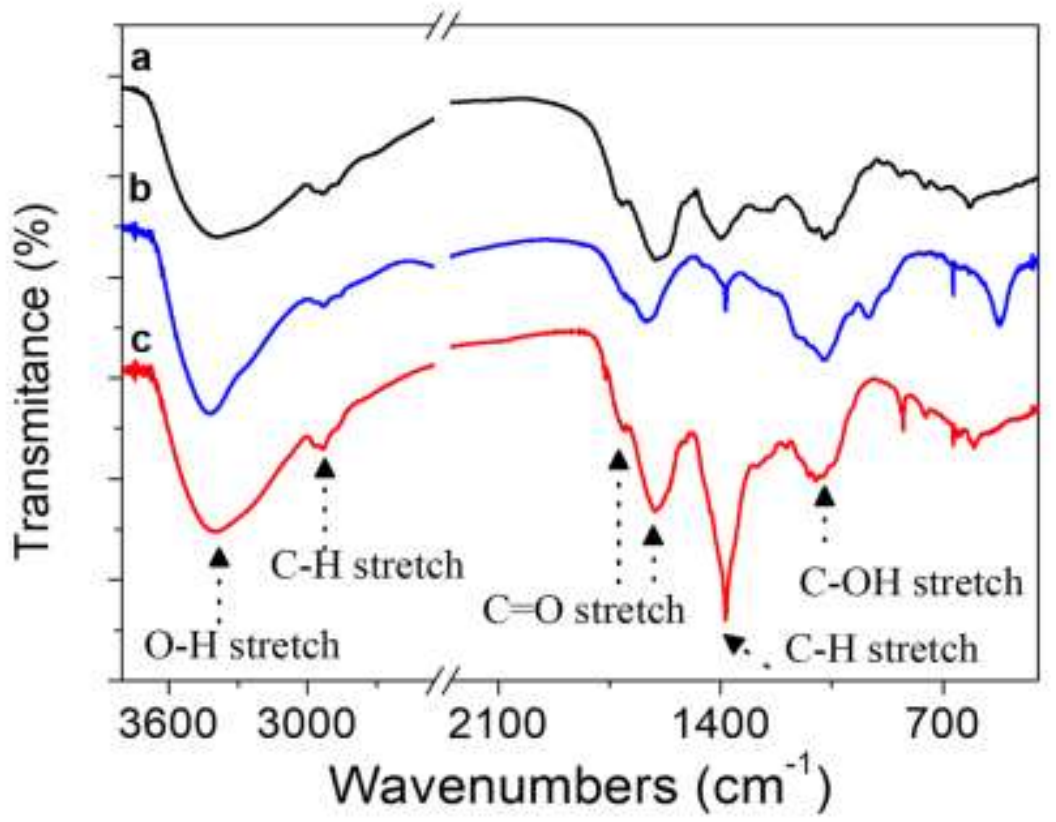

Figure 5. FTIR spectrum of aqueous extract of Lavandula dentata (a) and obtained nanoparticles with silver (b) and gold (c).

The FTIR of the Au (Figure $5 b$ ) and Ag nanoparticles (Figure $5 c$ ) revealed six bands at 3,420, 2,929, 1,630, 1,384, 1,073 and $619 \mathrm{~cm}^{-1}$ for LdAuNPs, and at 3,400, 2,929, 1,603, $1,384,1,076$ and $619 \mathrm{~cm}^{-1}$ for LdAgNPs, turn significant changes after the bioreduction. The strong absorption bands at around 3,420, 1,630 and 1,073 $\mathrm{cm}^{-1}$ were attributed to the $\mathrm{O}-\mathrm{H}$ stretching frequency of the phenolic group, the carbonyl group of amid I, and -C-N stretching of aliphatic amines or alcohol/phenol, respectively $(28,29)$. According to Issac et al. (30), the amines and alcohols present in the samples may have been responsible for the reduction and limitation of the gold and silver nanoparticles, related to the changes in the $1073 \mathrm{~cm}^{-1}$ area.

\section{Cell viability assay}

The effect of the aqueous extract of $L$. dentata on the cell viability of the K-562 cell line evaluated by the MTT reduction assay (Figure 6 ) showed a $40.1 \%$ reduction in cell viability. In the case of the nanoparticles obtained with that extract, the pure suspension presented a $36.1 \%$ reduction in cell viability for the nanoparticles produced with silver (LdAgNPs), and $76.2 \%$ when using the gold nanoparticles (LdAuNPs). The two formulations differed 
statistically from the control (Ctrl) $(p<0.0001)$ and from each other $(p<0.0001)$; however, only the LdAuNPs showed statistical difference with the extract $(p<0.0001)$.

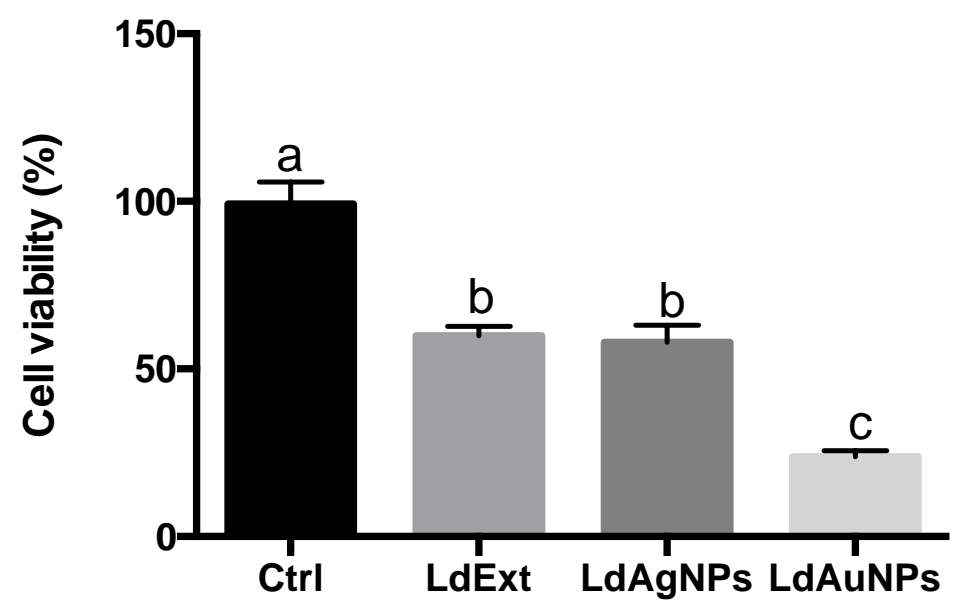

Figure 6. Cell viability of K-562 cell line with $72 \mathrm{~h}$ of treatment with the metallic nanoparticles. (Ctrl negative control, LdExt - Lavandula dentata aqueous extract, LdAgNPs - silver nanoparticles, LdAuNPs - gold nanoparticles).

It has previously been established in other studies that nanoparticles have cytotoxic potential in relation to several tumour lines. In 2008, Chen et al. [17] evaluated the cytotoxic activity of nanoparticles of hydroxyapatite; the results showed that the nanoparticles dramatically inhibited the proliferation of K-562 cells. In 2015, Shafagh et al. [18] evaluated the potential of copper oxide nanoparticles in relation to this strain and concluded that they led to a significant reduction in cell viability (57\%). However, metallic nanoparticles provide better results. Silver nanoparticles produced using Piper longum leaf extracts presented excellent cytotoxic effects on HEp-2 cell lines [19]. LdAgNPs produced with different aqueous extracts exhibited anticancer activity against HepG2 and PC3 cancer cell lines [20]. Namvar et al. [21] produced gold nanoparticles with Sargassum muticum water extract and confirmed cytotoxic activity in relation to the K-562 cell line by MTT assay. There are no existing studies that describe the development, cytotoxic assays or search of mechanisms of action of nanoparticles obtained from the aqueous extract of $L$. dentata and using the hydroalcoholic extract of $L$. dentata there are some possible molecular targets, already described, in cancer cells such as MMP-9, iNOS, COX-2, IL-1 $\beta$, IL-6 and TNFa [22].

\section{DISCUSSION}

Through the characterisation of the extract we were able to conclude that the aqueous extract of $L$. dentata has great potential for the reduction of metal ions due to the presence of hydroxybenzoic acids, hydroxycinnamic acids and derivatives, and flavonoids. In the UV-Vis analysis the nanoparticles presented a reduced size (about $20 \mathrm{~nm}$ ), a low level of polydispersion, and a homogenous spherical shape, which was confirmed by transmission microscopy, and atomic force microscopy. Infrared analysis suggested that amides and alcohols present in the samples may have been responsible for the reduction and limitation of the size of the silver and gold nanoparticles, as well as the predominantly crystalline characteristic suggested by the x-ray diffraction.

The cytotoxic assay demonstrated that the nanoparticles presented great potential to reduce the cell viability of $\mathrm{K}-562$, a myelogenous leukemia cell line, especially the gold 
nanoparticles (LdAuNPs). Furthermore, substances present in the aqueous extract of $L$. dentata may contribute to the treatment and reduction of the inflammatory activity of the pathological process of cancer.

Acknowledgments: This study was financed in part by the Coordenação de Aperfeiçoamento de Pessoal de Nível Superior - Brasil (CAPES) - Finance Code 001.

\section{REFERENCES}

1. Antunes FS, Dal'Acqua N, Bergmann CP, Giovanela M. Síntese, caracterização e aplicação de nanopartículas de prata como agentes antimicrobianos. Estudos Tecnológicos em Engenharia. 2013;9(1):20-6.

2. Junior MAM, Santos LSS, Gonçalves MC, Nogueira AF. Preparação de nanopartículas de prata e ouro: um método simples para a introdução da nanociência em laboratório de ensino. Química nova. 2012;35(9).

3. Neto EAB, Ribeiro C, Zucolotto V. Síntese de Nanopartículas de Prata para Aplicação na Sanitização de Embalagens. Comunicado Técnico. 2008;99.

4. Balasooriya ER, Jayasinghe CD, Jayawardena UA., Ruwanthika RWD, Silva RM, Udagama PV. Honey Mediated Green Synthesis of Nanoparticles: New Era of Safe Nanotechnology. Journal of Nanomaterials. 2017;2017.

5. Algieri F, Rodriguez-Nogales A, Vezza T, Garrido-Mesa J, Garrido-Mesa N, Utrilla MP, González-Tejero MR, Casares-Porcel M, Molero-Mesa J, Contreras MM, Segura-Carretero A, Pérez-Palacio J, Diaz C, Vergara N, Vicente F, Rodriguez-Cabezas ME, Galvez J. Anti-inflammatory activity of hydroalcoholic extracts of Lavandula dentata L. and Lavandula stoechas L. Journal of Ethnopharmacology. 2016;190:142-58.

6. Bousmaha L, Boti JB, Bekkara FA, Castola V, Casanova J. Infraspecific chemical variability of the essential oil of Lavandula dentata L. from Algeria. Flavour and Fragrance Journal. 2006;21(2):368-72.

7. Sossela FR, Zoppas BCA, Weber LP. Chronic Myeloid Leukemia: clinical aspects, diagnosis and main changes observed in complete blood count. Revista Brasileira de Análises Clínicas. 2017;49(2).

8. Mosmann T. Rapid colorimetric assay for cellular growth and survival: application to proliferation and cytotoxicity assays. Journal of Immunological Methods. 1983;16(65 (1-2)):55-63.

9. Elemike EE, Onwudiwe DC, Ekennia AC, Katata-Seru L. Biosynthesis, characterization, and antimicrobial effect of silver nanoparticles obtained using Lavandula x intermedia. Research on Chemical Intermediates. 2016.

10. Matsushita AFY, Inaba J, Fujiwara ST, Wohnrath K, Garcia JR, Pessoa CA. Synthesis and characterization of silver nanoparticles in the polymer 3-N-propyl pyridine silsesquioxane chloride for application in textile materials. Publicatio UEPG: Ciências Exatas e da Terra, Agrárias e Engenharias. 2012;18(1):39-50.

11. Bunghez IR, Fierascu RC, Dumitrescu O, Fierascu I, Ion RM. Characterization of silver nanoparticles obtained by Lavandula angustifolia extract. Revue Roumaine de Chimie. 2015;60(5-6): 515-9. 
12. Patra S, Mukherjee S, Barui AK, Ganguly A, Sreedhar B, Patra CR. Green synthesis, characterization of gold and silver nanoparticles and their potential application for cancer therapeutics. Materials Science and Engineering C. 2015;53:298-309.

13. Schaffazick SR, Guterres SS, Freitas LL, Pohlmann AR. Caracterização e estabilidade físico-química de sistemas poliméricos nanoparticulados para administração de fármacos. Química nova. 2003;26(5):726-37.

14. Alaqad K, Saleh TA. Gold and Silver Nanoparticles: Synthesis Methods, Characterization Routes and Applications towards Drugs. Journal of Environmental \& Analytical Toxicology. 2016;6(4).

15. Sun Y, Xia Y. Shape-Controlled Synthesis of Gold and Silver Nanoparticles. Science 2002, 298.

16. Kora A.J., Arunachalam J. Biosynthesis of silver nanoparticles by the seed extract of Strychnos potatorum: a natural phytocoagulant. IET Nanobiotechnology. 2013;7(3):83-9.

17. Chen P, Dai H, Han Y, Yin M, Li S. Effect of hydroxyapatite nanoparticles on K562 cells in vitro. Journal of Wuhan University of Technology-Mater. Sci. Ed. 2008;23(2):222-4.

18. Shafagh M, Rahmani F, Delirezh N. CuO nanoparticles induce cytotoxicity and apoptosis in human K562 cancer cell line via mitochondrial pathway, through reactive oxygen species and P53. Iranian Journal of Basic Medical Sciences. 2015;18(10):993-1000.

19. Jacob SJP, Narayanan JSFA. Synthesis of silver nanoparticles using Piper longum leaf extracts and its cytotoxic activity against Hep-2 cell line. Colloids and Surfaces B: Biointerfaces. 2012;91(1):212-214.

20. Prasannaraj G, Venkatachalam P. Green engineering of biomolecule-coated metallic silver nanoparticles and their potential cytotoxic activity against cancer cell lines. Advances in Natural Sciences: Nanoscience and Nanotechnology. 2017;8.

21. Namvar F, Rahman HS, Mohamad R, Rasedee A, Yeap SK, Chartrand MS, Azizi S, Tahir PM. Apoptosis Induction in Human Leukemia Cell Lines by Gold Nanoparticles Synthesized Using the Green Biosynthetic Approach. Journal of Nanomaterials. 2015;2015.

22. Linus LO, Hanson C, Alolga RN, Zhou W, Qi L. Targeting the key factors of inflammation in cancer: plant intervention. International journal of clinical and experimental medicine. 2017;10(12):15834-65.

(C) 5 (7) 2018 by the authors. Submitted for possible open access publication
under the terms and conditions of the Creative Commons Attribution (CC
BY NC) license (https://creativecommons.org/licenses/by-nc/4.0/). 